\title{
Osteoprotective effect of extract from Achyranthes japonica in ovariectomized rats
}

\author{
Jin-sung Kim', Sang-Won Lee', Su-Kang Kim², Sae-Won Na ${ }^{3}$, Young-Ock Kim ${ }^{1, *}$ \\ 'Department of Medicinal Crop Research Institute, National Institute of Horticultural \& Herbal Science, Rural Development Administration, Eumseong-gun, \\ Chungcheongbuk-do, Korea \\ ${ }^{2}$ Kohwang Medical Research Institute, School of Medicine, Kyung Hee University, Seoul, Korea \\ ${ }^{3}$ College of Veterinary Medicine, Chonbuk National University, Jeonju, Korea
}

This study was carried out to investigate the effects of the Achyrantes japonica ( $A$. japonica) extract on serum level of hormones from osteoporosis induced ovariectomized rats. Two month-old rats were ovariectomized (OVX), remained untreated for 8 weeks, and were subsequently administered $A$. japonica $(300 \mathrm{mg} / \mathrm{kg}$ ) every day for 8 weeks. We examined the effects of treated $A$. japonica every 10 days on ovariectomy-related changes in Insulin-like Growth Factors (IGF), Insulin-like Growth Factor binding protein-3 (IGBF-3), Estrogen, Calcium, and Phosporus. After 8 weeks, the serum levels of IGF-I, -II, and IGFBP-3 were higher presented as compared to the other two groups $(P<0.05)$, in the $A$. japonica extract treatment on OVX rats. Bone alkaline phosphatase levels were increased through $A$. japonica extract treatment in OVX rats compared to the other two groups. There were no differences between OVX and $A$. japonica extract treated OVX rats in serum levels of estrogen, but estrogen levels for the sham group were higher than for the other two groups. A. japonica extract is increased to serum levels of IGFs and IGFBP-3 of osteoporosis induced by ovariectomized rats. Thus, the results reveal that the $A$. japonica extract is a possible role for improvement of osteoporosis induced-ovariectomized rats and has a great potential as an alternative tool for the treatment of osteoporosis.

Keywords: Achyrantes japonica, Osteoporosis, Ovariectomy, Serum

\section{INTRODUCTION}

Osteoporosis is a silent, slowly progressive systemic skeletal disease (Epstein, 2006) and microarchitectural deterioration of bone tissue leading to increased bone fragility, and fractures (Christiansen, 1993). Postmenopausal women with osteoporosis occur estrogen deficiency. After menopause, the normal balance between bone formation and resorption is disrupted : osteoclasts (giant multi-nucleated cells) become more active, decreasing bone mass and increasing the chance of fracture. It is now known that postmenopausal osteoporosis should be regarded as a product of inflammatory disease triggered by estrogen deficiency (Chung et al., 2006).

Recently, therapy for osteoporosis is aimed at the prevention of further bone loss, primarily by inhibiting bone resorption. Particu- larly, insulin-like growth factors (IGF) and their binding proteins (IGFBP), which could modulate IGF's actions, might play essential roles in bone formation (Nilsson et al., 1994; Rosen et al., 1994). In serum, most IGF-1 (70-80\%) forms a $150-\mathrm{kD}$ complex by binding with IGFBP-3. The serum IGFBP-3 level is considered to positively regulated by GH and/or IGF-I, (Rosen and Pollak, 1999; Stewart and Rotwein, 1996). IGFBP-3 acts as a regulator of growth-dependent IGF-1 signaling through the enhancement of IGF-1 stability in serum (Binoux and Hossenlopp, 1988). A major part of bound IGF-I is connected to IGFBP-3 (Baxter, 1993). Low estrogen concentrations are known to increase the secretion of subsequent IGF-1 synthesis during early puberty. Estrogens initiate the pubertal growth spurt and stimulate skeletal growth. Hence, sex steroid-related changes in GH and IGF-1 secretion may impact
${ }^{*}$ Corresponding author: Young Ock Kim

Department of Medicinal Crop Research Institute, National Institute of Horticultural \& Herbal Science, Rural Development Administration,

76-3 Bisanri, Soymyen, Eumseong-gun, Chungcheongbuk-do 369-873, Korea

Tel: +82-43-871-5585, Fax: +82-43-871-5589, E-mail: kyo9128@korea.kr

Received: November 10, 2014 / Accepted: December 17, 2014
This is an Open Access article distributed under the terms of the Creative Commons Attribution Non-Commercial License (http://creativecommons.org/licenses/by-nc/3.0/) which permits unrestricted non-commercial use, distribution, and reproduction in any medium, provided the original work is properly cited. 
on bone size and cross-sectional area (Juul, 2001).

A. japonica also known as Japanese Chaff Flower is a perennial member of the Achyranthes genus in the Amaranthaceae family. It can be discovered on the roadside and its main distribution to Korea and Japan (Jung et al, 2007). The constituents of A. japonica are ecdysterone, inokosterone, and oleanolic acid (Bang et al., 2012; Kim et al., 2008). Physiological effects of $A$. japonica were the control of blood circulation, the removal of extravasated blood, and the softening of joint actions in humans and experimental animals (Marcone et al., 2003). A. japonica has been used in traditional medicine for the treatment of edema, arthritis and delayed menses. Currently, the primary therapeutic agents that stimulate bone formation (e.g., the growth factors, hormones, or fluoride compounds) and suppress bone resorption (e.g., bisphosphonates) can decrease the frequency of fracture. The ideal drug for osteoporosis prevention and treatment should increase the activity of osteoblasts and suppress the activity of osteoclasts.

Thus, this study was performed to study the serum levels of IGFs, IGFBP-3, TALP, BALP, estrogen and histomorphology in osteoporosis induced-ovariectomized rats. Ovariectomy (OVX) in the rat results in bone loss and micro- architecture deterioration (Ammann et al., 1996) and is the most commonly used animal model of post-menopausal osteoporosis (Turner et al., 2001).

\section{MATERIALS AND METHODS}

\section{Experimental animals}

The Sprague-Dawley rats were purchased from the Jungang Lab Animal Co. (Seoul, Korea). A total of 60 female rats, 3-month-old, weighing 190-210 g were randomly assigned into 3 groups (20 animals/group). (i) sham, (ii) OVX control, (iii) $17 \beta$-estradiol, (iv) A. japonica. Except $17 \beta$-estradiol, which was administered once daily i.p. for 8 weeks, each treatment sample was administered twice daily p.o. at a dose of $300 \mathrm{mg} / \mathrm{kg}$ for 8 weeks. The animals were housed in stainless steel cages having wire mesh bottom (4 animals per cage) in a light-controlled (12:12 h light-dark cycle) room with a constant temperature $\left(25^{\circ} \mathrm{C}\right)$. All the rats had free access to food and water. The animals in group I were sham operated. To induce menopause in rats, ovariectomies were performed in group I and group II. Ovariectomies were done under ketamine $\mathrm{HCl}(100 \mathrm{mg} / \mathrm{kg})$ and xylazine $(3 \mathrm{mg} / \mathrm{kg})$ anesthesia. During eight weeks, the animals of group I and II received solvent vehicle daily, whereas those of group III were administered A. japonica orally (300 $\mathrm{mg} / \mathrm{kg}$ ) daily for eight weeks. Body weight was determined weekly. The uterus was carefully dissected with the cervix attached, ex- cised, trimmed free of fat, transferred to a Petri dish on a moistened filter paper and covered with a lid. The uterus was then weighed immediately.

\section{Collection of blood and tissue samples}

Serum was isolated from the blood samples by centrifugation at $3,000 \times \mathrm{g}$ and $4^{\circ} \mathrm{C}$ for $5 \mathrm{~min}$ and stored at $-70^{\circ} \mathrm{C}$ for biochemical measurements. The tibia were dissected out and fixed in $4 \%$ paraformaldehyde in phosphate-buffered saline, followed by decalcification in $50 \mathrm{mM}$ EDTA and dehydration by immersion in 30\% sucrose. The bone samples were sectioned longitudinally at a thickness of $20 \mu \mathrm{m}$, using a freezing microtome (Leica, Nussloch, Germany). The sections were stored in $0.1 \mathrm{M}$ phosphate buffer at $4^{\circ} \mathrm{C}$.

Measurement of IGF-1 and IGFBP-3 levels in growth plates

To detect IGF-1 and IGFBP-3 expressions in the growth plate, the dehydrated tibia sections were permeabilized in $1 \%$ Triton X-100 and incubated with rabbit IGF-1 antibody and rabbit IGFBP-3 antibody (diluted 1:200; Santa Cruz Biotechnology, CA, USA) at room temperature overnight. Then, the sections were incubated with anti-rabbit antibody (diluted 1:200; Jackson ImmunoResearch Laboratories, West Grove, PA, USA) for $1 \mathrm{~h}$ and stained with $0.05 \%$ 3,3-diaminobenzidine. Finally, the sections were washed with $0.1 \mathrm{M}$ phosphate-buffered saline and mounted onto gelatinized glass slides.

\section{Measurement of serum IGF-1 and IGFBP-3 levels}

For the quantitative analysis of the serum IGF-I and IGFBP-3 levels, free IGF-1 and IGFBP-3 enzyme-linked immunosorbent assay (ELISA) kits were used according to the manufacturer's protocols (R\&D Systems, Minneapolis, MN, USA).

IGFBP-3, estrogen, $\mathrm{Ca}^{++}$and $\mathrm{P}$ assay

IGFBP-3 and estrogen were assayed using an immunoradiometric assay kit (Diagnostic Systems Laboratories, Webster, TX, USA). The $\mathrm{Ca}^{++}$and $\mathrm{P}$ assays used kits (Embiel Co, Gunpo, Korea).

\section{Measurement of femur/body weight}

Body and femur weight was measured every 10 days after $A$. japonica treatment in osteoporosis induced-ovariectomized rats using chemical balance (Ohaus, Parsippany, NJ, USA).

\section{Statistical analysis}

All the data were presented as mean \pm SD. The effects of the different treatments were compared by Student's t-test and were con- 
sidered significant for values of $P<0.05$. Post hoc analysis was carried out using Duncan's multiple-range test.

\section{RESULT}

\section{Animal model}

Body weight is shown in Fig. 1. Ovariectomy increased the body weight (Sham: $259.0 \pm 5.22$; ovariectomized: $312.86 \pm 10.27$; $17-\beta$ estradiol treated: $261.86 \pm 9.71(P<0.001)$ : $A$. japonica treated: $297.86 \pm 5.08$ ). There were no differences in body weights between sham, OVX and A. japonica- treated until the end of the study,

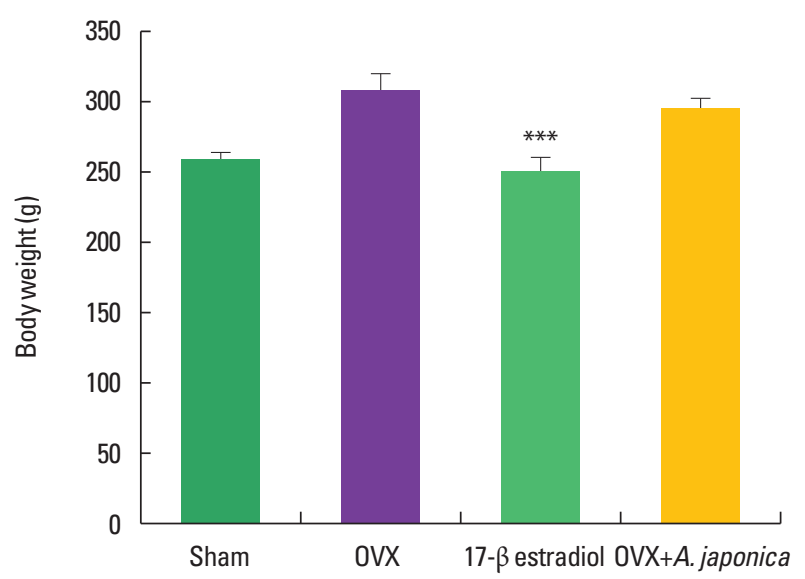

Fig. 1. Changes of body weight on OVX and $A$. japonica treatment. Values are mean \pm SEM. The number of animals is $7 /$ group. $P$-values denote significant difference from the OVX group and 17- $\beta$ estradiol treated group $(P<0.001)$. Sham: Normal and saline treated group, OVX: ovariectomized and saline treated group, $\mathrm{OVX}+A$. japonica: ovariectomized and $A$. japonicatreated group, OVX+17- $\beta$ estradiol: ovariectomized and 17- $\beta$ estradiol treated group.

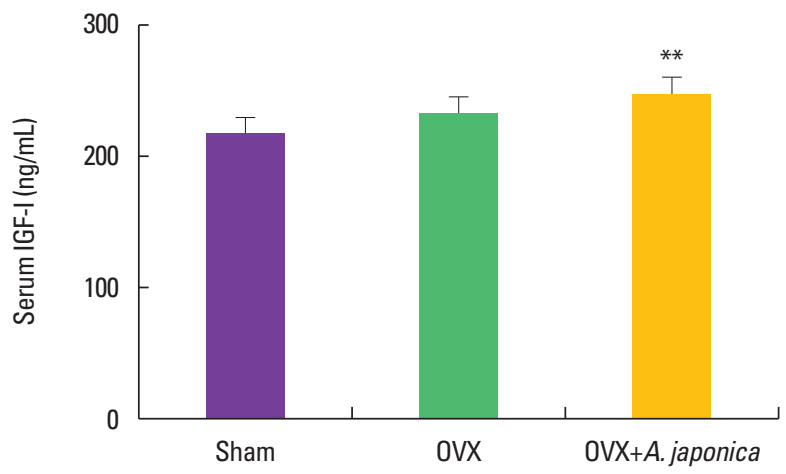

Fig. 2. Effects of OVX and $A$. japonica on serum IGF-I levels determined (300 $\mathrm{mg} / \mathrm{kg}$ ). Values are mean \pm SEM. The number of animals is $7 /$ group. $P$-values denote significant difference from the OVX group and $A$. japonica treated group $(P<0.01)$. Sham: Normal and saline treated group OVX: ovariectomized and saline treated group $\mathrm{OVX}+A$. japonica: ovariectomized and $A$. japonica treated group.
OVX higher weights than the other groups $(P<0.05)$. Body weight of OVX rats increased about $20.5 \%$, after 8 weeks surgery.

\section{Effect of ovariectomy and $A$. japonica on serum IGF-I levels}

Changes in serum level of IGF-1 A. japonica treatment in osteoporosis induced-OVX rat groups over time are shown in Fig. 2. On 8 weeks after ovariectomy, serum level of IGF-1 was significantly higher in the A. japonica treated OVX group than in the OVX and sham groups $(P<0.01)$ whereas slight changes were between the sham and OVX groups.

\section{Effect of ovariectomy and $A$. japonica on serum IGF-II levels}

Serum level of IGF-II after $A$. japonica treatment in osteoporosis

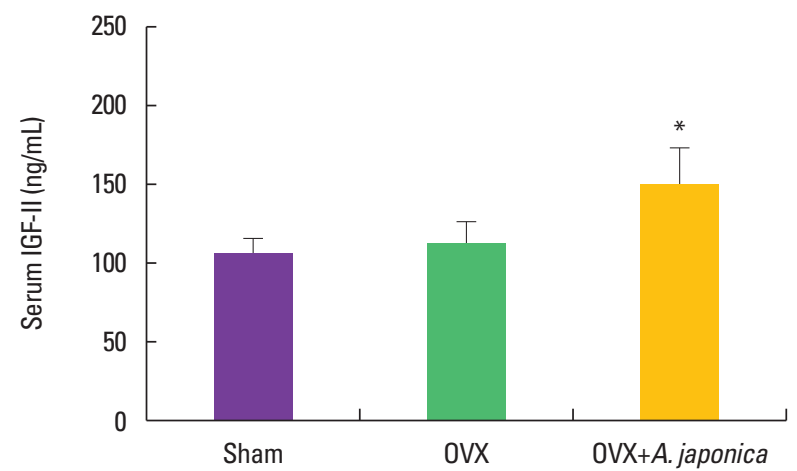

Fig. 3. Effects of OVX and A. japonica on serum IGF-II levels determined (300 $\mathrm{mg} / \mathrm{kg}$ ). Values are mean \pm SEM. The number of animals is $7 /$ group. $P$-values denote significant difference from the OVX group and $A$. japonica treated group $(P<0.05)$. Sham: Normal and saline treated group, OVX: ovariectomized and saline treated group, $\mathrm{OVX}+A$. japonica: ovariectomized and $A$. japonic treated group.

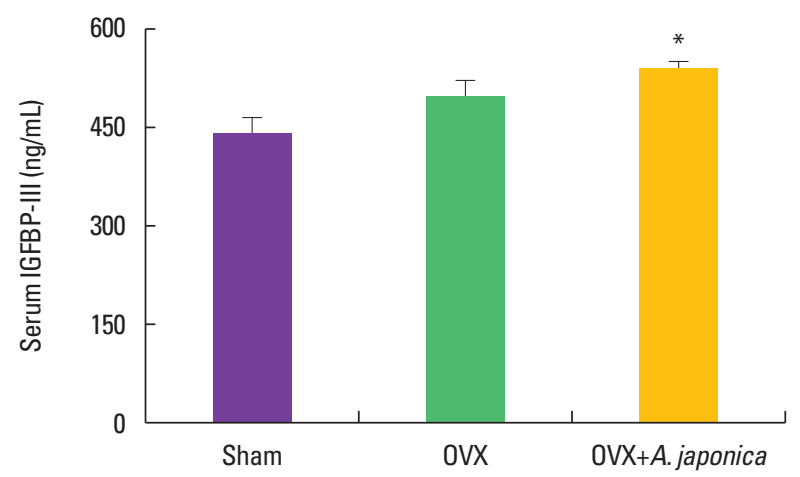

Fig. 4. Effects of OVX and $A$. japonica on serum IGBPF-III levels determined (300 $\mathrm{mg} / \mathrm{kg}$ ). Values are mean \pm SEM. The number of animals is $7 /$ group. $P$-values denote significant difference from the $\mathrm{OVX}$ group and $A$. japonica treated group $(P<0.05)$ Sham: Normal and saline treated group, OVX: ovariectomized and saline treated group, $\mathrm{OVX}+A$. japonica: ovariectomized and $A$. japonica treated group 
induced-OVX rat groups was shown in Fig. 3. On 8 weeks after ovariectomy, serum level of IGF-II on the A. japonica treated OVX group significantly increased compared with the sham group $(P<0.05)$, but there was slight difference between the sham and OVX groups.

\section{Effect of ovariectomy and $A$. japonica on serum IGFBP-3 and estrogen levels}

IGFBP-3 levels after A. japonica treatment in osteoporosis induced OVX rat groups are shown in Fig. 4. At 30 days, IGFBP-3 levels in the sham group significantly decreased and A. japonica treatment group increased compared with the OVX group $(P<0.05)$. Changes in estrogen levels of each group are shown in Fig. 5. On 8 weeks after ovariectomy, serum estrogen levels of each group was not difference as a consequence of OVX or the A. japon-

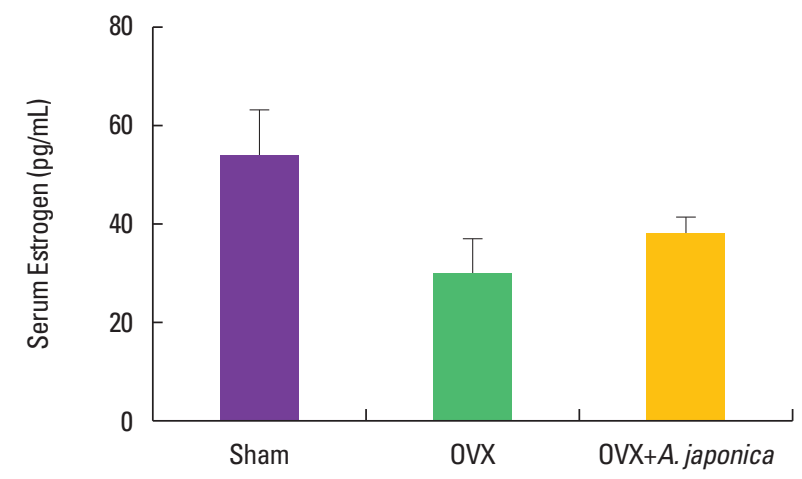

Fig. 5. Effects of OVX and $A$. japonica on serum estrogen levels determined (300 mg/kg). Values are mean \pm SEM. The number of animals is $7 /$ group. Sham: Normal and saline treated group, OVX: ovariectomized and saline treated group, $\mathrm{OVX}+A$. japonica: ovariectomized and $A$. japonica treated group.

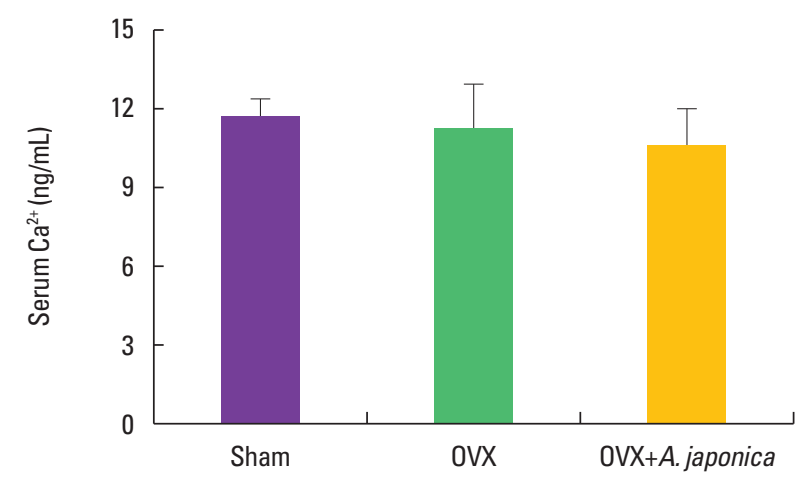

Fig. 6. Effects of OVX and A. japonica on serum $\mathrm{Ca}^{2+}$ levels determined (300 $\mathrm{mg} / \mathrm{kg}$ ). Values are mean \pm SEM. The number of animals is $7 / \mathrm{group}$. Sham: Normal and saline treated group, OVX: ovariectomized and saline treated group, $\mathrm{OVX}+A$. japonica: ovariectomized and $A$. japonica treated group. ica treated group, but there were differences between sham and other groups.

\section{Effect of ovariectomy and $A$. japonica on serum $\mathrm{Ca}^{++}$and $\mathrm{P}$ levels}

Changes in serum level of $\mathrm{Ca}^{++}$and $\mathrm{P}$ after $A$. japonica treated group over time are shown in Fig. 6 and Fig. 7. The serum levels of $\mathrm{Ca}^{++}$and $\mathrm{P}$ in all groups were not different in all days.

\section{Femur/body weight after $A$. japonica treatment in osteoporosis induced OVX rats.}

There was not statistically significant difference in femur/body weight among the three groups in all days (Fig. 8).

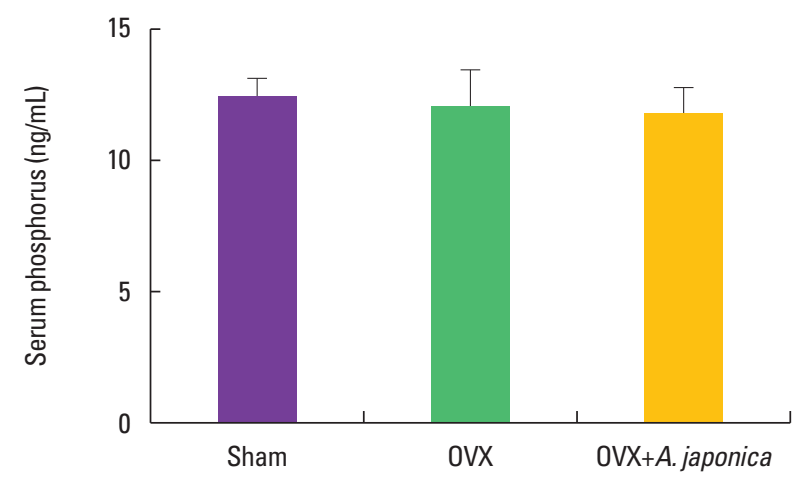

Fig. 7. Effects of $\mathrm{OVX}$ and $A$. japonica on serum estrogen levels determined (300 mg/kg). Values are mean \pm SEM. The number of animals is $7 /$ group. Sham: Normal and saline treated group, OVX: ovariectomized and saline treated group, $\mathrm{OVX}+A$. japonica: ovariectomized and $A$. japonica treated group.

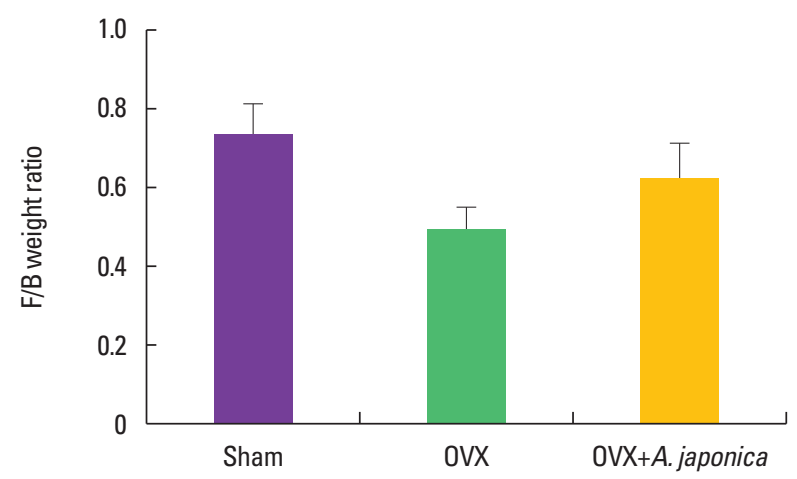

Fig. 8. Effects of $\mathrm{OVX}$ and $A$. japonica on $\mathrm{F} / \mathrm{B}$ weight ratio levels determined (300 mg/kg). Values are mean \pm SEM. The number of animals is $7 /$ group. Sham: Normal and saline treated group, OVX: ovariectomized and saline treated group, $\mathrm{OVX}+A$. japonica: ovariectomized and $A$. japonica treated group. 


\section{DISCUSSION}

This study showed that the A. japonica enlargements IGF/IGFBP on osteoporosis induced-ovariectomy rats. Circulating levels of IGF-I, -II is low in men and women with osteoporosis (Frystyk et al., 1994). Circulating level of IGF-I and IGFBP-3 were also low in males and females with oseoporosis due to decreasing of bone formation or increasing of bone reabsorption (Nasu et al., 1997). In serum IGF-II levels in A. japonica treated OVX rats increased in 8 weeks just as osteoblast differentiation and activity aid. IGF-II appears to be due to stimulatory effect of $A$. japonica on osteoblast and osteoclast bone formation in this study. Longitudinal bone growth is concern with the expression of various growth hormones $(\mathrm{GH})$. GH induces the IGF-1 expression in the liver, and circulating IGF-1 in serum stimulates skeletal growth (Yakar et al., 2002) and affects the expression of IGF-I in the bone (Roith et al., 2001). IGF-I induces cell proliferation via the action in the granulose cells of the ovary and the Leydig cells of the testis and increases the synthesis of the female hormones estradiol and progesterone and the male hormone testosterone, under the control of gonadotropic hormone (Kim et al., 2003). Estrogen plays an important act in mineral homeostasis, 'the deficiency of estrogen is recognized as a major factor in loss of bone minerals in postmenopausal osteoporosis (Danielsen and Flyvbjerg, 1996). Circulating levels of IGF-I, -II were low in men and women with osteoporosis (Frystyk et al., 1994). Circulating level of I IGF-I and IGFBP-3 were also low in males and females with oseoporosis due to decreasing of bone formation or increasing of bone reabsorption (Nasu et al., 1997) and increasing serum IGF-I levels of ovariectomized rats have been decreased (Rosen et al., 1994). We studied the increase of IGF-I during $A$. japonica treated osteoporosis compared with the OVX group after ovariectomy. IGF-I induces early osteoblast gene expression in human mesenchymal stem cells (Koch et al., 2005) and increased bone remodeling in transgenic mice with osteoblast targeted insulin-like growth factor-I (Jiang et al., 2006). In this study, OVX dramatically increases body weights, while A. japonica treatment presents almost normal levels. Although the mechanisms by which OVX induces an increase in body weight are not clear, estrogen deficiency induced body fat accumulation and subsequently caused an increase in body weight (Dang et al., 2002).

Therefore, this study indicates that effects of serum IGFs expression by treated A. japonica may be related to growth rate in OVX rats. In conclusion, $A$. japonica is able to prevent OVX-induced in bone loss, suggesting that $A$. japonica may be a reasonable natural alternative for the prevention of postmenopausal osteoporosis.

\section{CONFLICT OF INTEREST}

The authors declare that there are no conflicts of interest.

\section{ACKNOWLEDGMENTS}

This study was financially supported by the Medicinal Crops Division, Ginseng and Medicinal Plants Research Institute Rural Development Administrations (PJ010221).

\section{REFERENCES}

Ammann P, Rizzoli R, Meyer JM, Bonjour JP. Bone density and shape as determinants of bone strength in IGF-I and/or pamidronate-treated ovariecto- mized rats. Osteoporos Int 1996;6:219-227.

Bang SY, Kim JH, Kim HY, Lee YJ, Park SY, Lee SJ, Kim Y. Achyranthes japonica exhibits anti-inflammatory effect via NF- $\kappa B$ suppression and HO-1 induction in macrophages. J Ethnopharmacol 2012;144:109-117.

Baxter RC. Circulating binding proteins for the insulin like growth factors. Trends Endocrinol Metab 1993;4:91-96.

Binoux M, Hossenlopp P. Insulin-like growth factor (IGF) and IGF-binding proteins: comparison of human serum and lymph. J Clin Endocrinol Metab 1988;67:509-514.

Christiansen C. Consensus development conference: diagnosis, prophylaxis, and treatment of osteoporosis. Am J Med 1993;94:646-650.

Chung HY, Sung B, Jung KJ, Zou Y, Yu BP. The molecular inflammatory process in aging. Antioxid Redox Signal 2006;18:572-581.

Dang ZC, Van Bezooijen RL, Karperien M, Papapoulos SE, Lowik CW. Exposure of KS483 cells to estrogen enhances osteogenesis and inhibits adipogenesis. J Bone Miner Res 2002;17:394-405.

Danielsen CC, Flyvbjerg A. Insulin-like growth Factor I as a predictor of cortical bone mass a long-term study of ovariectomized an estrogen-treated rats. Bone 1996;19:493-498.

Epstein S. Epstein Update of current therapeutic options for the treatment of postmenopausal osteoporosis. Clin Ther 2006;28:151-173.

Frystyk J, Skjaerbaek C, Dinesen B, Orskov H. Free inslin-like growth factors (IGG-I and IGG-II) in human serum. FEBS Letters 1994;348:185191.

Jiang J, Lichtler AC, Gronowicz GA. Transgenic mice with osteoblast targeted insulin-like growth factor-I show increased bone remodeling. Bone 2006;39:494-504.

Jung SM, Choi SI, Park SM, Heo TR. Antimicrobial effect of Achyranthes japonica Nakai extracts against Clostridium difficile. Korean J Food Sci Technol 2007;39:564-568.

Juul A. The effects of oestrogens on linear bone growth. Hum Reprod 
Update 2001;7:303-313.

Kim J, Kim J, Kang D. A study on discriminative criteria of 6 kinds of Achyranthis radix using HPLC/DAD: isolation and identification of 20-hydroxyecdysone from Achyranthes japonica NAKAI and comparison of patterns of Achyranthis radix from different locations by HPLC. Koren J Herbol 2008;23:109-116.

Kim SH, Ku SY, Jee BC. Clinical efficacy of serum insulin-like growth factor-I (IGF-I), IGF-II, and IGF binding protein-3(IGFBP-3) in predicting the prognosis of in vitro fertilization and embryo transfer. Korean J Obstet Gynecol 2003;46:802-809.

Koch H, Jadlowiec JA, Campbell PG. Insulin-like growth factor-I induces early osteoblast gene expression in human mesenchymal stem cells. Stem Cells Dev 2005;14:621-631.

Marcone MF, Jahaniaval F, Aliee H, Kakuda Y. Chemical characterization of Achyranthes bidentata seed. Food Chem 2003;81:7-12.

Nasu M, Sugimoto T, Chihara M, Hiraumi M, Kurimoto F, Chihara K. Effect of natural menopause on serum levels of IGF-I and IGF-binding proteins : relationship with bone mineral density and lipid metabo- lism in perimenopausal woman. Eur J Endocrinol 1997;136: 608-616.

Nilsson A, Ohlsson C, Isaksson OG, Lindahl A, Isgaard J. Hormonal regulation of longitudinal bone growth. Eur J Clin Nutr 1994;48:150-158.

Roith DL, Bondy C, Yakar S, Liu JL, Butler A. The somatomedin hypothesis. Endocr Rev 2001;22:53-74.

Rosen CJ, Donahue LR, Hunter SJ. Insulin-like growth factors and bone: the osteoporosis connection. Proc Soc Exp Biol Med 1994;206:83-102.

Rosen CJ, Pollak M. Circulating IGF-I: New perspectives for a new century. Trends Endocrinol Metab 1999;10:136-141.

Stewart CE, Rotwein P. Growth, differentiation and survival: Multiple physiological functions for insulin-like growth factors. Physiol. Rev 1996;76:1005-1026.

Turner RT, Maran A, Lotinun S, Hefferan T, Evans GL, Zhang M, Sibonga JD. Animal models for osteoporosis. Rev Endocr Metab 2001;2:117127.

Yakar S, Rosen CJ, Beamer WG. Circulating levels of IGF-1 directly regulate bone growth and density. J Clin Invest 2002;110:771-781. 